\title{
Comments on sex determination from buccal mucosa scrapes
}

\author{
Balwant Rai
}

Received: 11 November 2008 / Accepted: 22 July 2009/Published online: 11 August 2009

(C) Springer-Verlag 2009

\section{Dear Sir,}

Barr bodies are known to arise from inactivation of the $\mathrm{X}$ chromosome in a female cell. This process of inactivation is known as lyonization. Barr bodies are named after the scientist Murray Barr who first described them [1]. The sex of the individual can easily be identified by the determination of Barr-body-positive cells. The technical note on sex determination from buccal mucosa scrapes by Mittal et al. [2] found that a relationship between the percentage of Barr-bodypositive cells and the age of the individual does not exist in both men and women. They also found that the percentage of Barr-body-positive cells ranged from $0 \%$ to $4 \%$ in male and from $20 \%$ to $78 \%$ in female. I think the patients' selection is not correct because in some syndromes such as in Klinefelter syndrome [3] and other disorders, males have Barr bodies as well as some disorders in females. I believe that during the study, the authors must do genetic and other diagnostic tests only on those patients (males) having positive Barr bodies. I believe these patients may have some genetic abnormality.
I believe that conclusions of the technical note are inconsistent with its recommendations in a number of respects, for example, the presence of Barr bodies in buccal mucosal cells could be determined with a fair degree of accuracy using the Papanicolaou staining technique, but the observation is contradictory as they observed that the Barr bodies were present in males and females. According to this statement, it should not be called sex determination, but sex estimation as in age estimation. I hope that the recently published technical note is not the conclusive word on this topic.

\section{References}

1. Anoop UR, Ramesh V, Balamurali PD, Nirima O, Premalatha B, Karthikshree VP (2004) Role of Barr bodies obtained from oral smears in the determination of sex. Indian J Dent Res 15:5-7

2. Mittal T, Saralaya KM, Kuruvilla A, Achary C (2008) Sex determination from buccal mucosa scrapes. Int.J. Legal Med. doi: 10.1007/s00414-008-0285-8

3. Pralea CE, Mihalache G (2007) Importance of Klinefelter syndrome in the pathogenesis of male infertility. Rev Med Chir Soc Med Nat Iasi 111(2):373-378
B. Rai $(\bowtie)$

Village-Bhangu, Distt-Sirsa,

Haryana, India

e-mail: drbalwantraissct@rediffmail.com 